\title{
Personalized Medicine: Ayurgenomics and Modern Medicine
}

\section{Dear Readers,}

Ayurveda is an ancient Indian school of medicine that uses a systems approach to understand and control health and disease. It has some interesting connections with modern personalised genomic medicine approaches to health and disease management. It is founded on the trisutra, which consists of three parts of causes, characteristics, and therapies that are linked by a single organising principle known as 'tridosha.' Tridosha is made up of three physiological entities: vata (kinetic), pitta (metabolic), and kapha (potential) that are found throughout the body, function together, respond to the environment, and maintain equilibrium. Each person is born with a unique proportion of tridosha that is determined not just by genetics but also by the environment during foetal development. To forecast the phenotypic repercussions of aberrations, modern medicine focuses on genetic, cellular, physiological, and environmental networks.

"Ayurgenomics" is an integrated method that combines Ayurvedic Prakriti notions with contemporary genetics research. It links the three doshas of vata, pitta, and kapha to the expression of genetic and physiological individuality. Ayurvedic medicine views each person as unique, and sickness as the result of a complex interaction of internal and external causes. Trisutra Ayurveda explains a core notion of prognosis and individualised strategy for healthy and unwell people.

The Ayurgenomics study thus presents a fresh molecular framework for merging genomics investigations with Ayurvedic concepts of inter-individual variability, thereby speeding up the finding of markers for predictive, preventative, and personalised therapy. Using the capabilities of genomics and molecular phenotyping, the Ayurgenomics technique enables for systematic research of Trisutra Ayurveda. Ayurgenomics may open the way to achieving preventive and personalised medicine aims more quickly.

Can ayurgenomics be used to diagnose and treat diseases? These, and many other questions, will have to be addressed in future research. It is our hope that a massive effort will be undertaken as soon as possible.
DOI: 10.5530/ijopp.15.1.1

Address for correspondence: Dr. Bhagya Venkanna Rao, Editor-in-chief, ijopp. Email Id: ijopp@emanuscript. in

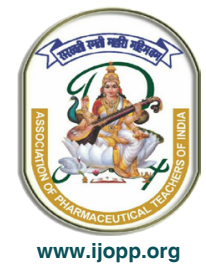

